\title{
Robotic Surgery and Its Application in Urology: A Journey Through Time
}

My chosen article for the Editor's Pick in this issue is 'Robotic Surgery and Its Application in Urology: A Journey Through Time' by Zaman et al. Robotic surgery is increasingly being performed worldwide, particularly in the management of oncological cases, and has decreased the learning curve compared to laparoscopy. It has various other advantages including decreased estimated blood loss, complications, duration of hospital stay, and improved functional outcomes for certain subjects. The future generation of young surgeons are attracted to the robotic surgery, particularly with new robotic platforms that will soon be on the market.

\section{A. Erdem Canda}

Professor of Urology, Department of Urology, School of Medicine, Koç University, İstanbul, Turkey
Authors:
*Mohammad Faruquz Zaman, ${ }^{1,2}$ Noor Buchholz, ${ }^{1}$ Christian Bach ${ }^{1,3}$,
1. U-merge Ltd. (Urology for emerging countries), London, UK
2. Department of Urology, Princess Alexandra Hospital, Harlow, UK
3. Department of Urology, University of Aachen, Germany
*Correspondence to Zaman17@hotmail.com

Disclosure:

The authors have declared no conflicts of interest.

Received:

09.01.21

Accepted:

23.07.21

Keywords:

Cost, learning curve, robot, surgery, training, uro-surgery.

Citation:

EMJ Urol. 2021;9[1]:72-82.

\section{Abstract}

Objectives: To evaluate an overview of the past, present, and future of robotic surgery. To provide insight and focus on the current status of the field of robotic systems for urological surgery with outcomes and discuss future perspectives in terms of other operative techniques and new robotic platforms.

Evidence acquisition: The authors undertook a non-systematic literature review using PubMed, Medline, and Google search. They used the search terms "robotic uro-surgery", "laparoscopic", "minimally invasive surgery", "future of robotics", "global robotic market growth", "geographical distribution", and "cost-effectiveness".

Evidence synthesis: Robotic surgery has embraced and extended almost all aspects of uro-surgical fields since its introduction three decades ago. There are definite advantages of robots to the surgeons and patients. It has become new standard of care for many surgical procedures. Innovation and technological advances are continuing and new with more precise robots are emerging. The major downside is cost. Despite the high cost, robot market is growing. 
Conclusion: Over the past decade, minimally invasive approaches have virtually revolutionised surgery and robotic surgery has accelerated these changes. Without doubt, robotic urologic surgery is here to stay and will expand further in all surgical disciplines. Utilisation of robotics should be coupled with a reduction in costs to healthcare systems, and improved clinical outcomes for the general population rather than a privileged few. Therefore, making this expensive technology more affordable must be part of the equation.

\section{INTRODUCTION}

Urology has long been recognised as a specialty that embraces technologic advances. From the earliest cystoscopes and resectoscopes to flexible ureteroscopes and laparoscopy, urologists have always been at the forefront in adopting and applying surgical technology. Hence, use of surgical robots to date has been dominated by urologists. Following the success of robot-assisted laparoscopic prostatectomy in the 1990s, robotic surgery has expanded into other domains of urological procedures worldwide. However, despite its acceptance and advantages, cost reductions are still needed.

This article explores the evolution of robotic surgery in urology over a timeline spanning the pre- and post-millennium periods. The authors also discuss potential future aspects in terms of technology, market expansion, cost, and geographical distribution.

\section{EVIDENCE ACQUISITION}

A non-systematic literature review was performed using PubMed/Medline and Google. The authors used the search terms "robotic", "laparoscopic", "minimally invasive uro-surgery", "future of robotics", "global robotic market growth", "geographical distribution", and "cost-effectiveness".

\section{EVIDENCE SYNTHESIS}

\section{Evolution of Robots and Robotic Surgery in the Pre-millennium Era (1950-2000)}

The concept of robotic intervention in medicine is not new. The Industrial Revolution of the late $18^{\text {th }}$ century became the instrumental phase in robotic advancement because it led to the development of key factors, including complex mechanics and electricity. In 1950, telepresence robotic arms were developed, which were direct precursors of today's surgical robots. They were initially used in hazardous environments, such as the bottom of the ocean or in space. Further rapid advances occurred in the 1980s, with development of technologies such as microelectronics, computing, digital imaging, video electronics, and display technology. The vision of a remote surgery programme targeted towards battlefield triage, funded by the USA Defense Advanced Research Projects Agency (DARPA), was the basis for the development of surgical robots.

The very first use of a surgical robot was by Kwoh et al.," who used the Programme Universal Machine for Assembly (PUMA) 560 robotic system to perform neurosurgical biopsies. Subsequently, Davies et al. ${ }^{2}$ performed a transurethral resection of the prostate by PROBOT, which was designed by using a rotating blade to complete prostatic resection. ${ }^{3}$ Despite initial success, the PROBOT failed to achieve widespread acceptance. Later, ROBODOC was designed to improve the precision of hip replacement surgery ${ }^{4}$ and then a robotic-assisted percutaneous access to the kidney device was developed to facilitate stone surgery ${ }^{5,6}$ (Table 1).

However, none of the above systems were designed for laparoscopic procedures, which first derived from a collaboration between the National Aeronautics and Space Administration's (NASA's) Ames Research Center (Mountain View, California, USA) and researchers from SRI International (formerly Stanford Research Institute; Menlo Park, California, USA). To reduce the mortality and morbidity of service personnel in conflict zones, the USA military recognised the concept of linking surgeons (distance from battlefield) to patients (on the battlefield). Computer Motion, Inc., (Santa Barbara, California, USA) developed the Automated Endoscopic System for Optimal Positioning (AESOP) robotic 
Table 1: Surgical robots in the pre-millennium era (non-laparoscopic and laparoscopic-assisted), post-millennium era, and current advanced versions.

\begin{tabular}{|c|c|c|}
\hline \multicolumn{3}{|c|}{ Surgical robot (non-laparoscopic) in pre-millennium era } \\
\hline $\begin{array}{l}\text { Arthrobot (the world's first surgical } \\
\text { robot) }\end{array}$ & For orthopaedic procedures & Canada (1983) \\
\hline PUMA 560 robotic system & $\begin{array}{l}\text { Accurate and precise neurosurgical } \\
\text { biopsy }\end{array}$ & Kwoh et al. (1988) \\
\hline $\begin{array}{l}\text { PROBOT (Integrated Surgical Supplies } \\
\text { Ltd. Mesa, Arizona, USA) }\end{array}$ & $\begin{array}{l}\text { Transurethral resection of the prostate } \\
\text { (did not gain clinical appeal); first } \\
\text { robot in urology }\end{array}$ & Imperial College London, UK (1988) \\
\hline ROBODOC (first active system) & Precise hip replacement surgery & $\begin{array}{l}\text { FDA approval (1988), first active } \\
\text { system }\end{array}$ \\
\hline Robotic PAKY-RCM & For percutaneous access of kidney & 1998 \\
\hline \multicolumn{3}{|c|}{ Surgical robot (laparoscopic-assisted) in pre-millennium era } \\
\hline AESOP & Robotic arm to assist laparoscopy & Computer Motion (1994) \\
\hline ZEUS robotic system & $\begin{array}{l}\text { Three robot arms with surgical control } \\
\text { centre, FDA-approved }\end{array}$ & Computer Motion (1998) \\
\hline da Vinci system & $\begin{array}{l}\text { 3D vision, EndoWrist technology, } \\
\text { Intuitive Motion technology, FDA- } \\
\text { approved }\end{array}$ & Intuitive Surgical, Inc. (2000) \\
\hline \multicolumn{3}{|c|}{ da Vinci surgical systems (2000-2010): post-millennium } \\
\hline Standard da Vinci (retired in 2019) & $\begin{array}{l}\text { First generation: surgeon } \\
\text { console, two robotic arms and } \\
\text { one camera holder, robot cart }\end{array}$ & FDA-approved 2000 \\
\hline First upgrade of da Vinci & $\begin{array}{l}\text { Three operating arms, one camera } \\
\text { holder, identical to initial system }\end{array}$ & FDA-approved 2003 \\
\hline da Vinci S & $\begin{array}{l}\text { HD vision, TilePro, multi-image display } \\
\text { features }\end{array}$ & FDA-approved 2006 \\
\hline da Vinci Si & $\begin{array}{l}\text { Better handling, increased range } \\
\text { of motion of arms (allowing bigger } \\
\text { surgical field), HD system, dual console }\end{array}$ & FDA-approved 2009 \\
\hline \multicolumn{3}{|c|}{ Current versions of da Vinci robots (2010-2020) } \\
\hline da Vinci Xi & $\begin{array}{l}\text { Articulating instrument, sharper 3D } \\
\mathrm{HD} \text {, arms are smaller and thinner, dual } \\
\text { console, single-port option }\end{array}$ & Released 2014 \\
\hline Fourth generation da Vinci X & $\begin{array}{l}\text { Uses voice and laser guidance to set } \\
\text { up, lightweight, integrated endoscopy, } \\
\text { simplified drape design }\end{array}$ & Released 2017 \\
\hline da Vinci SP surgical system & $\begin{array}{l}\text { Camera and instruments emerge } \\
\text { through the same port and triangulate } \\
\text { to avoid collisions at surgical field, } \\
\text { three multi-joint wristed instruments, } \\
\text { first fully wristed da Vinci system, 3D } \\
\text { HD camera }\end{array}$ & Released 2018 \\
\hline
\end{tabular}

AESOP: Automated Endoscopic System for Optimal Positioning; FDA: U.S. Food and Drug Administration; HD: high definition; PAKY: percutaneous access to the kidney; PUMA: Programmable Universal Machine for Assembly; RCM: remote centre of motion. 
platform, which helped surgeons position a laparoscopic camera by voice control. Further modifications resulted in the system being relaunched as the ZEUS operating system. ${ }^{7}$

Concurrently, Intuitive Surgical, Inc., (Sunnyvale, California, USA) released the Green Telepresence system, which became the early version of the current da Vinci system.

The two rival systems, ZEUS and da Vinci, pushed the frontiers of minimally invasive surgery. The da Vinci platform was first used on a human patient for a cholecystectomy, which was conducted by Jacques Himpens in 1997. ${ }^{8}$

The first laparoscopic radical prostatectomy with a remote-controlled robot (da Vinci) was performed by Abbou et al. ${ }^{9}$ in 2000 . The ZEUS and da Vinci system finally unified when Computer Motion, Inc., and Intuitive Surgical, Inc., merged in 2003. As a result, Intuitive Surgical, Inc., became the sole proprietor. Since then, the da Vinci system has dominated the world of robotic surgery for almost two decades. Newer technologies with improved versions of robots have emerged and are rapidly evolving the field (Table 1).

\section{Robots in the Post-millennium Era (2001-2010) and Current Version (2010-2020)}

The da Vinci platform produced various models for a decade. The first series of 50 robot-assisted radical prostatectomies was published by Menon et al. $^{10}$ in 2002, using the first-generation of the robot. Subsequently, upgraded versions of the da Vinci system entered the market with improved technology (Table 1).

Over the past 30 years, more than 21,000 peer-reviewed articles have confirmed the safety, efficacy, and benefits of the da Vinci system (Intuitive Annual Report, 7 Feb 2020). Despite the high capital investment and high costs for disposables, updated versions of the da Vinci robot are introduced into the market continuously (Table 1).

The total number of robotic platforms installed as of 315t December 2019 was 5,582. In addition, robotic procedures of various types in hospitals throughout the world numbered 1,229,000 (data on file; da Vinci Annual
Report, $7^{\text {th }}$ Feb 2020), an annual increase of approximately 20\%. Most surgical procedures performed robotically in the USA were in general surgery, followed by gynaecology and then urology. Conversely, outside the USA, most of the procedures were in urology.

\section{Training Platform to Improve Skills and Performances}

Approximately 400,000 deaths occur every year in the USA as a result of medical errors, making it the third-leading cause of death in the country. ${ }^{11,2}$ Surgical errors are common but potentially preventable. ${ }^{13}$ Adequate surgical skills and techniques have been directly related to patient outcomes. . $^{13,14}$

Robot-assisted surgery in urology is growing. The development of structured and validated training programmes is important in order to gain adequate skills and prevent poor surgical outcomes and medico-legal issues.

\section{Technical and non-technical skills}

The da Vinci robotic platform is complex and expensive. Therefore, users should be properly trained and certified. A recent paper calculated that 100-180 robotic operations are required to obtain better, or at least equivalent, results compared with open surgery..$^{15}$ Another article quoted a learning curve of 8-150 procedures. ${ }^{16}$ However, surgeons experienced in both open radical prostatectomy and laparoscopic radical prostatectomy can make smooth and quicker transitions to robotics. ${ }^{17}$

Robotic platforms require both console training and patient side training. Patient side training involves patient positioning, establishing pneumoperitoneum, port placement, robot docking, and basic laparoscopic skills. Console training requires dry and wet lab simulations and supervised operating. To improve skills and performance, a variety of structured curriculums have been developed to shorten the learning curve. ${ }^{18,19}$

Non-technical skills (e.g., teamwork, leadership, and decision-making skills) are an integral part of surgical training and should be developed in parallel with the development of technical skills. One study showed that $86 \%$ of adverse surgical events were due to system 
errors rather than technical skills. ${ }^{20}$ Furthermore, $40 \%$ of intraoperative errors were related to failures in communication. ${ }^{20}$

Intuitive Surgical, Inc., provide integrated training with virtual simulation, data-driven optimisation, and customised solutions. Over the last 20 years, a robust training programme has therefore been built-up. This time-tested, comprehensive training programme can help develop the skills essential to using da Vinci technology.

\section{A pathway to gain technical and clinical skills: two steps and four phases}

Initially, optimisation of proficiency by developing knowledge and skills to use da Vinci technology. Second, progress with a surgeon-led series of procedures focused on clinical application, advanced techniques, and procedure refinement.

Firstly, training is centred on the core system and advanced technology. This consists of two phases: introduction to da Vinci technology (familiarisation with the system through 'test drives', videos, and live case observations) and da Vinci technology training (the development of technical skills via online learning, simulation, and hands-on training).

The second step is focused on progressive peer-to-peer clinical skill advancement and again consists of two phases: an initial case series plan (the integration of da Vinci technology into practice with support from experienced proctors) and continuing development (the expansion of skills through mentoring, surgeonled programmes, and simulation).

However, a variety of new robotic systems from numerous countries are coming onto the stage. Several console-based robots for laparoscopic multi- and single-port surgery with various modifications of robotic arms, instruments, haptic feedback, eye tracking, and video technology will soon emerge. These developments with new robotic platforms would require precise, operation-specific teaching and training that could potentially be different from the current da Vinci training curriculum. In the future, the range of simulation platforms is likely to increase, with a variety of robotic training programmes and robotic simulated tasks.

\section{Types and Levels of Robots with New Platforms}

There are three main types of robotic systems currently in use in surgery: active, semi-active, and master-slave systems (Table 2).

Active systems essentially work autonomously (while remaining under the control of the operative surgeon) and undertake preprogramed tasks. The PROBOT and ROBODOC platforms are two examples.

Semi-active systems allow for a surgeon-driven element to complement the pre-programmed element of the robot system.

Master-slave systems (the da Vinci and ZEUS platforms) do not have any pre-programmed or autonomous elements.

Currently, available robots are completely dependent on human control. Attempts are being made to program the robot to operate, at least for parts of the procedure, independently (Table 2 ).

In future, robots may be equipped with artificial intelligence to independently perform procedures, or parts of it, by autonomous robot-assisted surgery to overcome operatordependent variations and improve patient care. However, use of autonomous technology will come at the cost of sacrificing meaningful human control and at the expense of uro-surgical jobs. Robot-assisted surgery systems with various levels of autonomy have already been developed (Table 2).

\section{Evidence Supporting Robot-Assisted Surgery in Urological Procedures}

The majority of robotic procedures are radical prostatectomy, radical cystectomy, partial nephrectomy, and pyeloplasty. Below, the authors explore the implementation of robotassisted surgery.

\section{Robot-assisted radical prostatectomy}

The first robot-assisted radical prostatectomy (RARP) was performed in 2000. The first series of 50 RARPs was published in 2002. ${ }^{10}$ Subsequently, numerous articles have been published. Several meta-analyses demonstrated a significant advantage in terms of potency, continence, and 
Table 2: Types and different levels of robotic systems.

\begin{tabular}{|c|c|c|c|}
\hline Types of surgical robot & Action & Example & Criteria \\
\hline Master-slave system & $\begin{array}{l}\text { First (stereotaxis) and } \\
\text { second (endoscopic) } \\
\text { generation }\end{array}$ & $\begin{array}{l}\text { da Vinci system } \\
\text { ZEUS system }\end{array}$ & $\begin{array}{l}\text { Entirely dependent on } \\
\text { surgeon's activity }\end{array}$ \\
\hline Semi-active system & Surgeon-driven & $\begin{array}{l}\text { Acrobot and Rio } \\
\text { (orthopaedic) }\end{array}$ & $\begin{array}{l}\text { Partially autonomous, haptic } \\
\text { feedback }\end{array}$ \\
\hline Active system & $\begin{array}{l}\text { Robot-driven under control } \\
\text { of surgeon }\end{array}$ & $\begin{array}{l}\text { PROBOT } \\
\text { ROBODOC }\end{array}$ & $\begin{array}{l}\text { (Surgeon-controlled) } \\
\text { autonomous } \\
\text { Non-haptic }\end{array}$ \\
\hline \multicolumn{4}{|c|}{ Classification of robotic system with various level of autonomy } \\
\hline Level 0 & No autonomy & $\begin{array}{l}\text { Teleoperated robot: AESOP } \\
\text { and ZEUS systems }\end{array}$ & $\begin{array}{l}\text { Follow command (operator } \\
\text { performs all tasks) }\end{array}$ \\
\hline Level 1 (direct control) & $\begin{array}{l}\text { Passive assistance during a } \\
\text { task }\end{array}$ & $\begin{array}{l}\text { da Vinci } \\
\text { Trauma Pod }\end{array}$ & $\begin{array}{l}\text { Robot provides some } \\
\text { assistance during a task but } \\
\text { remains under full human } \\
\text { control }\end{array}$ \\
\hline Level 2 (shared control) & $\begin{array}{l}\text { Autonomy for part of the } \\
\text { task }\end{array}$ & $\begin{array}{l}\text { AquaBeam ablation (BPH) } \\
\text { Acrobot }\end{array}$ & $\begin{array}{l}\text { Robot performs a task but is } \\
\text { monitored by surgeon }\end{array}$ \\
\hline $\begin{array}{l}\text { Level } 3 \text { (conditional } \\
\text { autonomy) }\end{array}$ & $\begin{array}{l}\text { Different autonomous task } \\
\text { strategies (autonomy for } \\
\text { specific tasks) }\end{array}$ & $\begin{array}{l}\text { Flexible endoscopic robot } \\
\text { Autonomous bowel } \\
\text { anastomosis }\end{array}$ & $\begin{array}{l}\text { Appropriate task/surgical } \\
\text { plan is approved or selected } \\
\text { by surgeon. Robot performs } \\
\text { tasks without close } \\
\text { oversight }\end{array}$ \\
\hline $\begin{array}{l}\text { Level } 4 \text { (supervised } \\
\text { autonomy; high autonomy) }\end{array}$ & $\begin{array}{l}\text { Robot is able to perform } \\
\text { entire procedure ('robotic } \\
\text { resident') }\end{array}$ & $\begin{array}{l}\text { Radiosurgery } \\
\text { ROBODOC (total knee } \\
\text { arthroplasty) } \\
\text { PROBOT (TURP) }\end{array}$ & $\begin{array}{l}\text { Robot is able to make } \\
\text { decisions under supervision }\end{array}$ \\
\hline Level 5 (full autonomy) & $\begin{array}{l}\text { Robot performs entire } \\
\text { surgery, no human/surgeon } \\
\text { is needed. } \\
\text { Independent robotic } \\
\text { surgeon }\end{array}$ & NA & $\begin{array}{l}\text { Still surgical fiction } \\
\text { No surgeon needs to be in } \\
\text { the loop }\end{array}$ \\
\hline
\end{tabular}

Acrobot: Active Constraint Robot; AESOP: Automated Endoscopic System for Optimal Positioning; BPH: benign prostate hyperplasia; RIO: Robotic-Arm Interactive Orthopedic System; TURP: transurethral resection of the prostate.

blood transfusion for RARP compared with open and laparoscopic approaches. ${ }^{21,22}$

Robotic surgery has revived the perineal approach for radical prostatectomy and Kaouk et al. $^{23}$ presented an overview of the recent advances based on their experience with RARP.

Robotic surgery is also implemented for the surgical treatment of benign prostatic hyperplasia ${ }^{24}$ and low-risk cancer with lower urinary tract symptoms due to prostate enlargement. ${ }^{25}$

\section{Robot-assisted radical cystectomy}

Radical cystectomy with pelvic lymphadenectomy and urinary diversion is the standard of care for treating organ-confined muscle-invasive bladder cancer and refractory non-invasive disease. Despite high morbidity and the risk of perioperative mortality, open 
radical cystectomy remains the gold standard. ${ }^{26}$ Minimally invasive techniques are gaining momentum and popularity because they provide similar oncological outcomes with lower morbidity. The first series of robot-assisted radical cystectomies (RARCs) was reported by Menon et al. ${ }^{27}$ in 2003. Since then, there has been a dramatic increase in utilisation of RARC, from under $1 \%$ of all cystectomies performed in the USA in 2004 to approximately $23 \%$ in $2014 .^{28}$

The two most recent meta-analyses found no differences regarding oncological outcomes between RARC and open radical cystectomy, but a lower 90-day complication rate, a lower transfusion rate, a shorter time to flatus, and a greater lymph node yield in patients who underwent RARC. ${ }^{29,30}$

As part of RARC, many centres are still conducting an extracorporeal urinary diversion through an abdominal mini-incision. Complete intracorporeal urinary diversion seems to fully unlock the potential of RARC. Yet, despite already being performed in some expert centres worldwide, this approach is still considered as experimental by the European Association of Urology (EAU). ${ }^{31}$ Brassetti et al..$^{32}$ reported one of the largest series with long-term data about RARC with totally intracorporeal urinary diversion.

\section{Robot-assisted radical nephrectomy}

Laparoscopic radical nephrectomy is the gold standard and recommended by the EAU for patients with $\geq T 2$ renal tumours. ${ }^{33}$ No significant differences in post-operative complications have been observed between robotic-assisted radical nephrectomy (RARN) and laparoscopic radical nephrectomy; ${ }^{34}$ however, robotic surgery is associated with a prolonged operating time and higher hospital costs. Despite this, the use of robot-associated nephrectomy in the USA increased from $1.5 \%$ in 2003 to $27.0 \%$ in $2015 .{ }^{34}$

Over the last decade, robots have been used to operate on patients with advanced renal cell carcinoma with inferior vena cava thrombus. RARN with inferior vena cava thrombectomy is a complex procedure that requires a multimodal approach involving urological, cardiothoracic, and hepatobiliary surgeons. Patients are traditionally treated with open surgery with large abdominal or thoracoabdominal incisions. RARN with inferior vena cava thrombectomy was first reported by Abaza et al. ${ }^{35}$ Recently, Gill et al. ${ }^{36}$ presented a series of 16 patients with Level II and III inferior vena cava thrombus with good outcomes.

\section{Robot-assisted partial nephrectomy}

Robot-assisted partial nephrectomy is considered the gold standard for most small renal tumours. A meta-analysis of 4,919 patients from 25 studies showed decreased complications, less conversions to open surgery, reduced positive surgical margin rates, and a shorter warm ischaemia time in the robotic group relative to their laparoscopic counterparts. ${ }^{37}$ Complex tumours of $>4 \mathrm{~cm}$ with high nephrometry scores are increasingly being managed using the robotic approach, with good oncological outcomes. ${ }^{38}$ Robot-assisted partial nephrectomy has proven feasible and superior to conventional laparoscopy even in solitary kidneys, multifocal renal masses, and for new or recurrent tumours in a kidney previously treated with partial nephrectomy. ${ }^{39}$

\section{Robot-assisted nephroureterectomy}

Nephroureterectomy is almost the ideal procedure to demonstrate the advantages of minimally invasive surgery in terms of cosmetics and post-operative use of analgesics.

A recently published review, despite showing some perioperative advantages for minimally invasive access, found no statistically significant differences between the laparoscopic and the robotic approach, and consequently called for larger, better designed randomised controlled trials. ${ }^{40}$

Veccia et al. ${ }^{41}$ reported a systematic review and meta-analysis of comparative outcomes of robotic versus other established nephroureterectomy techniques.

\section{Robot-assisted retroperitoneal lymphadenectomy}

Open retroperitoneal Iymphadenectomy (RPLND) is still the gold standard based on oncologic outcomes and long-term follow-up data. However, complications and morbidity from open RPLND incision affect $3.7-10.0 \%$ of patients. Therefore, the demand for minimally invasive surgery for cosmetic reasons is 
increasing. The first case of laparoscopic RPLND was described in 1992 and that of robotic RPLND in 2006. Thirteen studies subsequently suggested that functional outcomes and infield recurrence rates may be comparable to open approaches. ${ }^{42}$ A large case series of 47 patients with low-risk non-seminomatous germ cell tumours showed a 9\% perioperative complication rate, preservation of ejaculation in $100 \%$ of patients, and a recurrence-free rate of 97\% at 16 months. ${ }^{43}$ Another study showed no retroperitoneal recurrences at 22 months and a minor complication rate (Clavien-Dindo Grade II) of $17 \% .{ }^{44}$ Rocco et al. $^{45}$ reported the largest series of primary robot-assisted RPLND for nonseminomatous germ cell tumours.

\section{Robot-assisted pyeloplasty}

The published data regarding robot-assisted pyeloplasty show excellent results and success rates (of 94-100\%), as well as very good results in redo operations after failed primary procedures (with success rates of $78-94 \%$ ). A meta-analysis of nine published studies on 277 robotic cases and 196 laparoscopic cases showed no differences between the two techniques apart from a shorter operative time for the robotic operation. ${ }^{46}$

\section{Robot-assisted laparoscopic ureteric re-implantation}

Over the past decade, there has been an increasing shift toward robot-assisted laparoscopic distal ureteric reimplantation. The first reported robot-assisted laparoscopic ureteric re-implantation was performed by Yohannes et al. ${ }^{47}$ in 2003. A recent review by Asghar et al. ${ }^{48}$ in 2020 showed advantages in terms of blood loss, length of hospital stays, and post-operative pain for the robotic compared with the open approach.

\section{Under scrutiny: recent expansion of other robotic uro-surgery procedures}

Robotic surgery is being explored for adrenal surgery. Heger et al. ${ }^{49}$ recently published a meta-analysis of 1,710 patients who underwent either a minimally invasive (robotic or laparoscopic) or an open adrenalectomy. Blood loss was lowest in the robotic group. A significant reduction in the length of stay compared with conventional laparoscopy was also recorded. Ye et al. ${ }^{50}$ described a novel robotic adrenal enucleation technique.

Two randomised trials comparing laparoscopic and robot-assisted sacrocolpopexy showed higher costs, a longer operative time, and more post-operative pain in the robotic group. ${ }^{51}$

Robotic platforms have allowed lymph node dissection for several genitourinary cancers. ${ }^{52}$ In children, the success rate of robotic-assisted surgery for the treatment of vesicoureteral reflux was below $90 \%$ whereas the success rate of open extravesical ureteric re-implantation was approximately $98 \% .^{53}$

\section{The Future of Robotic Surgery}

Despite the high cost of robots, there is a continuing expansion of robotic surgical procedures. Although adoption of robots for surgery was introduced in the 1990 s, only $15.1 \%$ of all common operations in the USA are performed robotically (increased from 1.8\% in 2012 to $15.0 \%$ in 2018). ${ }^{54}$ Robotic-assisted laparoscopic prostatectomy increased from $0.7 \%$ in 2003 to $42.0 \%$ in $2010^{55}$ and by 2014 , RARP accounted for up to $90 \%$ across the USA. ${ }^{56}$ However, this figure is likely to be much lower outside America.

The global market for surgical robots keeps growing. The initial capital investment for a da Vinci system is 1.2-1.5 million USD, with an annual maintenance cost of 100,000 USD and an average disposable instrument cost of 1,400-1,700 USD per case. Bolenz et al. ${ }^{57}$ compared costs for a RARP with laparoscopic and open procedures. They calculated the costs of RARP, laparoscopic RP, and open RP as 9,450 USD, 5,687 USD, and 4,437 USD per operation, respectively.

As there are no competitors, da Vinci do not yet have to compromise on the cost because of their monopoly. A centre needs to perform 100150 cases of robot-assisted surgeries per year to be cost-effective. ${ }^{58}$ The fastest growing Asian and other developers are coming to the market with low-cost surgical robots that will soon challenge the expensive da Vinci monopoly while also providing the same or better surgical outcomes (Table 3).

Western countries have possibly already reached, or will soon reach, the peak and plateau 
Table 3: Recent and future emerging robotics in urology.

\begin{tabular}{|c|c|c|c|}
\hline Company & Target technology & Configuration & Current status \\
\hline \multicolumn{4}{|l|}{ USA } \\
\hline $\begin{array}{l}\text { da Vinci Xi (Intuitive } \\
\text { Surgical, Inc., Sunnyvale, } \\
\text { California, USA) }\end{array}$ & MIS, multi-port & $\begin{array}{l}\text { Master console, four arms, } \\
\text { and patient cart }\end{array}$ & FDA-approved 2014 \\
\hline $\begin{array}{l}\text { da Vinci X (Intuitive Surgical, } \\
\text { Inc., Sunnyvale, California, } \\
\text { USA) }\end{array}$ & MIS, multi-port & $\begin{array}{l}\text { Master console, four arms, } \\
\text { and patient cart }\end{array}$ & FDA-approved 2017 \\
\hline $\begin{array}{l}\text { da Vinci SP (Intuitive } \\
\text { Surgical, Inc., Sunnyvale, } \\
\text { California, USA) }\end{array}$ & MIS, single-port & $\begin{array}{l}\text { Master console, one arm, } \\
\text { and patient cart }\end{array}$ & FDA-approved 2018 \\
\hline $\begin{array}{l}\text { Senhanse (TransEnterix, Inc., } \\
\text { Morrisville, North Carolina, } \\
\text { USA) }\end{array}$ & MIS, multi-port & $\begin{array}{l}\text { Master console and } \\
\text { separated arms }\end{array}$ & FDA-approved 2017 \\
\hline $\begin{array}{l}\text { Monarch Platform (Auris } \\
\text { Health, Inc., Redwood City, } \\
\text { California, USA) }\end{array}$ & NOTES & $\begin{array}{l}\text { Master console, one arm, } \\
\text { and patient cart }\end{array}$ & Clinical trial \\
\hline \multicolumn{4}{|l|}{ Europe } \\
\hline $\begin{array}{l}\text { Verisus (CMR Surgical, } \\
\text { Cambridge, UK) }\end{array}$ & MIS, multi-port & $\begin{array}{l}\text { Master console, four arms, } \\
\text { and patient cart }\end{array}$ & Under development \\
\hline $\begin{array}{l}\text { Roboflex Avicenna (Elmed } \\
\text { Medical Systems, Inc., } \\
\text { Ankara, Turkey) }\end{array}$ & Remote ureteroscopy & $\begin{array}{l}\text { Master console, robot } \\
\text { manipulates conventional } \\
\text { ureteroscope }\end{array}$ & $\begin{array}{l}\text { Approved for } \\
\text { ureterorenoscopy } 2014\end{array}$ \\
\hline $\begin{array}{l}\text { DLR MicroSurge (German } \\
\text { Aerospace Center [DLR], } \\
\text { Cologne, Germany) }\end{array}$ & MIS & $\begin{array}{l}\text { Master-slave } \\
\text { telemanipulation, two haptic } \\
\text { input device, three arms, } \\
\text { 3D camera, visual and force } \\
\text { feedback }\end{array}$ & Clinical Trial \\
\hline $\begin{array}{l}\text { Surgenius (Surgica } \\
\text { Robotica, Trieste, Italy) }\end{array}$ & MIS & $\begin{array}{l}\text { Master-slave } \\
\text { telemanipulation, haptic } \\
\text { feedback }\end{array}$ & Under development \\
\hline \multicolumn{4}{|l|}{ ASIA } \\
\hline $\begin{array}{l}\text { Revo-I (Meere Company, } \\
\text { Hwaseong-Si, Gyeongg, } \\
\text { South Korea) }\end{array}$ & MIS, multi-port & $\begin{array}{l}\text { Master console, four arms, } \\
\text { and patient cart }\end{array}$ & $\begin{array}{l}\text { Currently, clinical use in } \\
\text { South Korea only }\end{array}$ \\
\hline $\begin{array}{l}\text { RIVERFIELD Inc., (Shinjuku } \\
\text { City, Tokyo, Japan) }\end{array}$ & MIS, multi-port & $\begin{array}{l}\text { Master console, four arms, } \\
\text { and patient cart }\end{array}$ & Under development \\
\hline $\begin{array}{l}\text { EndoMaster (EndoMaster } \\
\text { Pte Ltd., Singapore) }\end{array}$ & NOTES & $\begin{array}{l}\text { Master console, one arm, } \\
\text { and patient cart }\end{array}$ & Clinical trial \\
\hline $\begin{array}{l}\text { Micro Hand S robot system } \\
\text { (Tianjin University, China) }\end{array}$ & MIS, multi-port & NA & Under development \\
\hline \multicolumn{4}{|l|}{ CANADA } \\
\hline $\begin{array}{l}\text { SPORT surgical system, } \\
\text { (Titan Medical Inc., Toronto, } \\
\text { Canada) }\end{array}$ & MIS, multi-port/LESS & $\begin{array}{l}\text { Master console, one arm and } \\
\text { patient cart, two articulated } \\
\text { instruments, haptic system, } \\
\text { 3D HD flexible camera }\end{array}$ & Under development \\
\hline
\end{tabular}

FDA: U.S. Food and Drug Administration; LESS: laparoendoscopic single-port surgery; MIS: minimally invasive surgery; NA: not applicable; NOTES: natural orifice transluminal endoscopic surgery; SPORT: Single Port Orifice Robotic Technology. 
level for the installation of new robots. The AsiaPacific and South American markets are the target of future robot installations and expected to grow very fast. Currently, differences in surgical robot density are marked.

In Brazil, there is one robot per 5.1 million people, in Europe there is one robot per 998,000 people, and in the USA there is one robot per 112,000 people. ${ }^{59}$ Moreover, in emerging countries, most robotic platforms are usually concentrated in affluent cities and at private healthcare institutions. Only affluent patients pay out of their pocket because insurance, if it even exists, does not cover the cost of robotic operations.

However, the ongoing COVID-19 crisis will likely be followed by a global recession in the near future. The costs of robotic surgery have become the prominent factor driving treatment and investment decisions. The COVID-19 pandemic led to a 40\% reduction in its shares on the stock market in late March 2020. Globally, procedures performed using the da Vinci surgical system decreased by $19 \%$ worldwide in Quarter 2 of 2020 compared with 2019 because elective procedures were either cancelled or postponed. Quarter 3 revenue was 1.1 billion USD, down $4 \%$ from last year. During Quarter 3, Intuitive Surgical, Inc., shipped 195 new da Vinci surgical systems, a $29 \%$ decline from the same quarter in 2019. The global robotic surgery market is expected to decline from 5.04 billion USD in 2019 to 4.84 billion USD in 2020 , which is a decrease of $3.91 \%$ from 2019 , as a consequence of the COVID-19 crisis. The market will eventually stabilise and is expected to reach 7.71 billion USD in 2023.60

A future ideal robotic system should be cost-effective, easy to use, easy to set up, and portable so that it can be used in different locations and settings.

The main limitation of this article is that it is a non-systematic literature review; therefore, there is a possibility of subjective bias.

\section{CONCLUSION}

Over the past decade, minimally invasive approaches have revolutionised surgery, and robotic surgery has accelerated these changes. Without doubt, robotic urologic surgery is here to stay and will expand further in all surgical disciplines. Utilisation of robotics should be coupled with a reduction in costs to healthcare systems and improved clinical outcomes for the general population rather than a privileged few. Therefore, making this expensive technology more affordable must be part of the equation.

\section{References}

1. Kwoh YS et al. A robot with improved absolute positioning accuracy for CT guided stereotactic brain surgery. IEEE Trans Biomed Eng. 1988;35(2):153-61.

2. Davies BL et al. The development of a surgeon robot for prostatectomies. Proc Inst Mech Eng H. 1991;205(1):358.

3. Harris SJ et al. The PROBOT - an active robot for prostate resection. Proc Inst Mech Eng H. 1997;211(4);31725.

4. Cowley G. Introducing ROBODOC: a robot finds his calling in the operating room. Newsweek. 1992;120(21):86.

5. Bzostek A et al., "An automated system for precise percutaneous access of the renal collecting system" Troccaz J et al. (eds.), International Conference on Computer Vision, Virtual Reality and Robotics in Medicine, International Conference on Medical Robotics and ComputerAssisted Surgery (2005), Grenoble:
SpringerGrenoble. pp.299-308

6. Cadeddu JA et al. Stereotactic mechanical percutaneous renal access. J Endourol. 1998;12(2):121.

7. Falcone $\mathrm{T}$ et al. Full Robotic assistance for Laparoscopic tubal anastomosis: a Case Report. J Laparosendos Adv Surg Tech. 1999;9(1):107-13.

8. Himpens $\mathrm{J}$ et al. Telesurgical laparoscopic cholecystectomy. Surg Endosc. 1998;12(8):1091

9. Abbou CG et al. Remote laparoscopic radical prostatectomy carried out with a robot: report of a case. Prog Urol 2000;10(4):520-3.

10. Menon A et al. Laparoscopic and robot assisted radical prostatectomy: establishment of a structured program and preliminary analysis of outcomes. J Urol. 2002;168(3):945-9.

11. James JT. A new, evidence-based estimate of patient harms associated with hospital care. J Patient Saf.
2013;9(3):12-8.

12. Heron M. Deaths: leading causes for 2016. Natl Vital Stat Rep. 2018;67(6):177

13. Jabbour $\mathrm{N}$, Snyderman $\mathrm{CH}$. The economics of surgical simulation. Otolaryngology Clin North Am. 2017;50:1029-36.

14. Birkmeyer JD et al. Surgical skill and complication rates after bariatric surgery. N Engl J Med. 2013;369:143442.

15. Yaxley JW et al. Robot-assisted laparoscopic prostatectomy versus open radical retropubic prostatectomy: early outcomes from a randomised controlled Phase 3 study. Lancet. 2016;388(10049):105766.

16. Bach $\mathrm{C}$ et al. Training in Robotics: The learning curve and contemporary concepts in training. Arab J Urol. 2014;12(1):58-61.

17. Dasgupta $P$ et al. Transition 
from open to robotic-assisted radical prostatectomy. BJU Int. 2008;101(6):667-8

18. Ahmed $\mathrm{K}$ et al. Development of a standardised training curriculum for robotic surgery: a consensus statement from an international multidisciplinary group of experts. BJU Int. 2015;116(1):93-101.

19. Lovegrove $\mathrm{C}$ et al. Structured and modular training pathway for robotassisted radical prostatectomy (RARP): validation of the RARP assessment score and learning curve assessment. Eur Urol. 2016;69(3):52635.

20. Gawande AA et al. Analysis of errors reported by surgeons at three teaching hospitals. Surgery. 2003;133(6):614-21.

21. Novara G et al. Systematic review and meta-analysis of studies reporting oncologic outcome after robotassisted radical prostatectomy. Eur Urol. 2012:62(3):382-404

22. Novara $\mathrm{G}$ et al. Systematic review and meta-analysis of perioperative outcomes and complications after robot-assisted radical prostatectomy. Eur Urol. 2012;62(3):431-52

23. Garisto J et al. The evolution and resurgence of perineal prostatectomy in the robotic surgical era. World J Urol. 2020;38(4):821-8.

24. Meyer D et al. Rationale for roboticassisted simple prostatectomy for benign prostatic obstruction. Eur Uro Focus. 2018;4(5):643-7.

25. Pathak RA, Hemal AK. Management of low-risk prostate cancer in patients with enlarged glands and lower urinary tract symptoms: robotic total prostatectomy, a novel technique. World J Urol. 2020;38(4):829-36.

26. Svatek RS et al. Risk factor analysis in a contemporary cystectomy cohort using standardized reporting methodology and adverse event criterias. J Urol. 2010;183(3):929-34.

27. Chang $S$ et al. The impact of robotic surgery on the surgical management of prostate cancer in the USA. BJU Int. 2015;115(6):929-36.

28. Burger $M$ et al. Epidemiology and risk factors of urothelial bladder cancer. Eur Urol. 2013;63(2): 234-41.

29. Son SK et al. Safety and effectiveness of robot-assisted versus open radical cystectomy for bladder cancer: a systematic review and meta-analysis. J Laparoendosc Adv Surg Tech A. 2017;27(11):1109-20.

30. Steffens D et al. Robotic surgery in uro-oncology: a systematic review and meta-analysis of RCTs. Urology. 2017:106:9-17.

31. Witjes A et al. Updated 2016 EAU guidelines on muscle-invasive and metastatic bladder cancer. Eur Urol. 2017;71(3):462-75

32. Brassetti A et al. Long-term oncologic outcomes of robot-assisted radical cystectomy (RARC) with totally intracorporeal urinary diversion (ICUD): a multi-center study. World J Urol. 2020;38(4):837-43.

33. Ljungberg $B$ et al. EAU guidelines on renal cell carcinoma: 2014 update. Eur Urol. 2015;67(5):913-24.

34. Jeong $G$ et al. Association of robotic-assisted vs laparoscopic radical nephrectomy with perioperative outcomes and health care costs, 2003 to 2015. JAMA. 2017;318(16):1561-8.

35. Abaza R. Initial series of robotic radical nephrectomy with vena caval tumor thrombectomy. Eur Urol. 2011;59(4):652-6

36. Gill IS et al. Robotic Level III inferior vena cava tumor thrombectomy: initial series. J Urol. 2015;194(4):92938.

37. Leow JJ et al. Outcomes of robotic versus laparoscopic partia nephrectomy: an updated metaanalysis of 4,919 patients. J Urol. 2016;196(5):1371-7. James JT. A new, evidence-based estimate of patient harms associated with hospital care. $J$ Patient Saf. 2013;9(3):122-8.

38. Gupta GN et al. Robot-assisted laparoscopic partial nephrectomy for tumors greater than $4 \mathrm{~cm}$ and high nephrometry score: feasibility, renal functional, and oncological outcomes with minimum 1-year follow-up. Urol Oncol. 2013;31(1):51-6.

39. Novara G et al. Robot-assisted partial nephrectomy. Int J Surg. 2016;36(Pt C):554-9.

40. Mullen E et al. Systematic review of open versus laparoscopic versus robot-assisted nephroureterectomy. Rev Urol. 2017;19(1):32-43.

41. Veccia A et al. Robotic versus other nephroureterectomy techniques: a systematic review and meta-analysis of over 87,000 cases. World J Urol. 2020;38(4):845-52.

42. Hiester A et al. Robot assisted retroperitoneal lymph node dissection for small volume metastatic testicular cancer. J Urol. 2020;204(6):1242-8

43. Cheney SM et al. Robot-assisted retroperitoneal lymph node dissection: technique and initial case series of 18 patients. BJU Int. 2015;115(1):114-20.

44. Nakamura T et al. Post-chemotherapy laparoscopic retroperitoneal lymph node dissection is feasible for Stage IIA/B non-seminoma germ cell tumors. Int J Clin Oncol. 2016;21(4):791-5.

45. Rocco NR et al. Primary robotic RPLND for nonseminomatous germ cell testicular cancer: a two-centre analysis of intermediate oncologic and safety outcomes. World J Urol. 2020:38(4):859-67.

46. Autorino R et al. Robot-assisted and laparoscopic repair of ureteropelvic junction obstruction: a systematic review and meta-analysis. Eur Urol. 2014;65(2):430-52

47. Yohannes P et al. Rapid communication pure robot assisted laparoscopic ureteral reimplantation for ureteral stricture disease: case report. J Endourol. 2003;17(10):891-3.

48. Asghar A et al. Robot-assisted distal ureteral reconstruction for benign pathology: current state. Investig Clin Urol. 2020;61(Suppl 1):S23-32.

49. Heger $P$ et al. Evaluation of open and minimally invasive adrenalectomy: a systematic review and network meta-analysis. World J Surg. 2017;41(11):2746-57.

50. Ye $\mathrm{C}$ et al. Robotic enucleation of adrenal masses: technique and outcomes. World J Urol. 2020;38(4):853-8.

51. Committee opinion no. 628: robotic surgery in gynecology. Obstet Gynecol. 2015;125(3):760-7.

52. Pini $\mathrm{G}$ et al. Robot assisted lymphadenectomy in urology: pelvic, retroperitoneal and inguinal. Minerva Urol Nefrol. 2016;69(1):38-55.

53. Cannon GM, Ost MC. Robotassisted laparoscopic extravesical ureteral reimplantation for primary vesicoureteral reflux in children. J Urol. 2017;197(6):1379-81.

54. Sheetz $\mathrm{K}$ et al. Trend in the adoption of robotic surgery for common surgical procedures. JAMA Netw Open. 2020;3(1):e1918911.

55. SL Cheng et al. The impact of robotic surgery on the surgical management of prostate cancer in the USA. BJU Int. 2015;115(6):929-36.

56. Kolata G. Results unproven, robotic surgery wins converts. 2010. Available at: https://www.nytimes. com/2010/02/14/health/14robot html?pagewanted=print\& $r=0 \% E 3 \% 80 \% 89$. Last Accessed: July 282021.

57. Bolenz $\mathrm{C}$ et al. Cost comparison of robotic, laparoscopic, and open radical prostatectomy for prostate cancer. Eur Urol. 2010;57(3):453-8.

58. Ramsay $\mathrm{C}$ et al. Systematic review and economic modelling of the relative clinical benefit and costeffectiveness of laparoscopic surgery for removal of the prostate in men with localised prostate cancer. Health Technol Assess. 2012;16(41):1-313.

59. Moldes $\mathrm{J}$ et al. Pediatric robotic surgery in South America: advantage and difficulties in program implementation. Front Pediatr. 2019;DOI:10.3389/fped.2019.00094.

60. Research and Markets. Robotic surgery devices global market report 2020-2030: COVID-10 growth and change. 2021. Available at: https://www.researchandmarkets. com/reports/5309350/roboticsurgery-devices-global-market. Last Accessed: 28 July 2021 